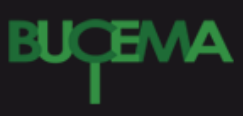

Bulletin du centre d'études médiévales d'Auxerre | BUCEMA

Hors-série $n^{\circ} 7 \mid 2013$

Les nouveaux horizons de l'ecclésiologie : du discours clérical à la science du social

\title{
La eclesiología de Marsilio de Padua
}

Julio A. Castello Dubra

\section{(2) OpenEdition}

1 Journals

Edición electrónica

URL: https://journals.openedition.org/cem/12781

DOI: $10.4000 /$ cem. 12781

ISSN: 1954-3093

Editor

Centre d'études médiévales Saint-Germain d'Auxerre

Referencia electrónica

Julio A. Castello Dubra, «La eclesiología de Marsilio de Padua », Bulletin du centre d'études médiévales d'Auxerre | BUCEMA [En ligne], Hors-série $n^{\circ} 7$ | 2013, mis en ligne le 21 mars 2013, consulté le 04 mars 2023. URL : http://journals.openedition.org/cem/12781 ; DOI : https://doi.org/10.4000/cem.12781

Este documento fue generado automáticamente el 4 marzo 2023.

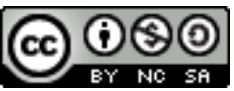

Creative Commons - Attribution - Pas d'Utilisation Commerciale - Partage dans les Mêmes Conditions 4.0 International - CC BY-NC-SA 4.0

https://creativecommons.org/licenses/by-nc-sa/4.0/ 


\title{
La eclesiología de Marsilio de Padua
}

\author{
Julio A. Castello Dubra
}

1 El Defensor pacis de Marsilio de Padua ha tenido una formidable repercusión en la crítica moderna. Durante mucho tiempo el debate estuvo dominado por la cuestión de la presunta "modernidad" de Marsilio respecto de sus tesis sobre la fuente del poder político, el origen de la sociedad, la naturaleza de la ley, etc. No fue ese, sin embargo, el objeto que despertó la atención de sus contemporáneos. En efecto, las tempranas condenaciones y réplicas que mereció el Defensor pacis se concentraron sobre su peculiar interpretación de la autoridad de Pedro, la distinción entre el sacerdote y el obispo, y, en general, la subordinación de la jerarquía eclesiástica al Emperador ${ }^{1}$.

El objetivo del Defensor pacis es expreso: refutar la doctrina de la plenitudo potestatis del papa, en términos de Marsilio, la pretensión del pontífice romano de tener una jurisdicción coactiva - esto es, política- de alcance universal, más precisamente, por sobre el "Emperador de los romanos". La obra tiene su motivación directa en el conflicto político entre el Emperador Luis de Baviera y el polémico papa Juan XXII. Pero aunque se trate de una obra de circunstancia, tampoco se reduce a un mero panfleto de un publicista. La obra contiene al mismo tiempo un complejo desarrollo teórico y argumentativo, una revisión no menor de fuentes escriturarias e históricas y, por momentos, una funcionalidad retórica, lo que la hace difícil de encasillar en un género determinado.

3 La doctrina papal es presentada por Marsilio como una singular "causa de discordia" que afectó y afecta al "Imperio romano", es calificada como una "perversa opinión [...], ocasionalmente derivada de un efecto admirable, posterior al tiempo de Aristóteles, producido por la causa suprema más allá de la posibilidad de la naturaleza inferior y de la acción usual de las causas en las cosas" ${ }^{2}$, en otros términos, es una derivación incorrecta, que pretende deducir arbitrariamente del hecho sobrenatural de la venida de Cristo y la consecuente institución de la Iglesia y su sacerdocio, una prerrogativa política ilegítima para el presunto sucesor de Pedro, el obispo de Roma ${ }^{3}$. Como esta causa de discordia representa, en cuanto tal, un cruce entre el ámbito de las causas naturales que acontecen regularmente, de las cuales se ocupa la ciencia civil, y el ámbito de la intervención inmediata y extraordinaria de Dios, es natural que su 
completa refutación exija, por una parte, un primer discurso racionalmente demostrativo y concluyente acerca de los fundamentos naturales de la legitimidad del poder político - que corresponde al desarrollo de la primera dictio del Defensor pacis-; y por la otra, un segundo discurso que formule, mediante una adecuada interpretación de los fundamentos escriturarios, una correcta comprensión de la función y el sentido del sacerdocio cristiano y de la jerarquía eclesiástica en general -que comprende la segunda dictio del Defensor pacis. En esta extensa segunda sección es donde se concentran las principales tesis de la eclesiología de Marsilio.

\section{Los contenidos de la segunda dictio del Defensor pacis}

4 En su revisión del papel de la Iglesia y de su modo de inserción en el mundo temporal, Marsilio no pretende conmover ninguna de sus bases doctrinarias. Marsilio se mueve dentro de los presupuestos básicos que caracterizan al pensamiento medieval anterior a la Reforma. Lejos está de querer quebrar la universalidad de la fe cristiana, o de suplantar el magisterio de la Iglesia como una instancia de autoridad que determina los contenidos fundamentales de la fe, por más que haya de proponer alguna variante respecto del lugar en que reside esa instancia. En sus argumentaciones Marsilio se apoya en el cuerpo dogmático tradicional de la Iglesia y aspira a hablar siempre desde el punto de vista de la verdad de la fe católica. Establecidas cuáles son las escrituras que deben considerarse canónicas, habrá que ajustarse sólo a ellas y a la autoridad de los santos intérpretes y los doctores aprobados de la fe cristiana.

Del mismo modo, aunque Marsilio proteste enérgicamente contra el estado de corrupción moral y las ambiciones materiales de los miembros del clero de su época, tampoco es su intención someter a la Iglesia a un proceso de "desinstitucionalización" que la reduzca a una comunidad puramente mística y carente de un aparato de gobierno externo. Marsilio no parece interesado en eliminar el papel del sacerdocio como indispensable mediador en la relación entre Dios y los hombres. Por el contrario, su interés principal es precisamente determinar cuál ha de ser la estructura institucional de la Iglesia acorde con una interpretación correcta de su sentido trascendente y con su desarrollo histórico durante el tiempo en que éste se ajustó al ideal originario, es decir, antes de que se verificaran las malinter pretaciones que culminaron en la "perversa" interpretación papal del gobierno de la Iglesia. Lejos de luchar contra la institucionalización de la Iglesia, Marsilio pretende, mas bien, reemplazar un modelo de institucionalización por otro ${ }^{4}$.

\section{La institución originaria del sacerdocio}

6 Lo primero que formula Marsilio es una revisión, sobre la base de fundamentos escriturarios, de la institución originaria del sacerdocio por parte de Cristo. Al respecto, sostendrá: (i) que Cristo no vino al mundo a gobernar a los hombres bajo un régimen coactivo; (ii) que no sólo se excluyó a sí mismo y a sus discípulos de tal tipo de autoridad, sino que se sometió él mismo, real y personalmente, a los príncipes y autoridades de este mundo; y (iii) que enseñó a sus discípulos a hacer lo propio. A Marsilio le basta con remitirse al sentido místico de la misión de Cristo puesto en sus propias palabras: “... mi reino no es de este mundo" ${ }^{5}$, su misma conducta ante el juicio de Pilatos ${ }^{6} \mathrm{y}$ la célebre expresión respecto al tributo debido al César ${ }^{7}$. La doctrina 
concordante de los apóstoles confirma el reconocimiento del origen divino del poder y del sentido providencial de su institución, resumida en la célebre sentencia de Pablo: "Todos deben someterse a las autoridades constituidas, porque no hay autoridad que no provenga de Dios y las que existen han sido establecidas por él." ${ }^{8}$ Con esta desvinculación del contenido político en la función del sacerdocio Marsilio no hace más que abundar en sus propios principios acerca de la naturaleza de la ley. En efecto, para Marsilio, tanto la ley humana como la ley divina son "preceptos coactivos" ${ }^{9}$, esto es, mandatos obligatorios que prevén un castigo para sus transgresores; pero así como la ley humana sólo lo hace con respecto a este mundo, la ley divina sólo puede hacerlo con respecto al próximo. Por lo tanto, en nada beneficiaría para la obtención de la vida eterna -que es el fin de los preceptos de la ley divina- la institución de un poder coactivo para lograr lo que los hombres deben observar libremente: en otras palabras, en este mundo, la fe no puede imponerse mediante la coacción ${ }^{10}$.

\section{La distinción entre los dos aspectos del sacerdocio}

7 Pertenece a la tradición común de la baja Edad Media la distinción, dentro del sacerdocio, entre dos tipos de autoridad: la potestas ordinis y la potestas jurisdictionis. La primera se refiere a los poderes carismáticos que corresponden propiamente al "orden sagrado", es decir, las facultades relativas a la administración de los sacramentos; en tanto que la otra se refiere a los poderes estrictamente jurisdiccionales sobre la base de los cuales se constituye la jerarquía eclesiástica: la autoridad superior de los obispos por sobre los sacerdotes o diáconos y, en especial, la del papa sobre el conjunto de la Iglesia ${ }^{11}$. Marsilio no introduce una novedad por el hecho de traer a colación esta distinción, sino por el modo en que la interpreta. La potestas clavium concedida por Cristo a Pedro, sobre la cual el papado basaba su poder jurisdiccional, es restringida por Marsilio al solo ámbito de la potestas ordinis. La potestad "de atar y desatar" se refiere, en la interpretación de Marsilio, a la habilitación especial que tiene el sacerdote en la administración de los sacramentos de la confesión y la eucaristía. Este aspecto del sacerdocio es el único que reconoce un origen sobrenatural, puesto que consiste en un "carácter" o sello impreso en el alma del sacerdote por parte de Dios ${ }^{12}$.

Pero hay que subrayar que el ejercicio de esta autoridad por parte del sacerdote no comporta ningún juicio coactivo, ni siquiera respecto de la ley divina, puesto que el único juez de ella es el Juez Supremo. El sacerdote es "juez" en la primera y no en la tercera de las significaciones en las que Marsilio clasifica el término ${ }^{13}$ : como experto o perito en cualquier arte o disciplina, en este caso, en la ley divina. De allí la recurrencia con la que Marsilio compara al sacerdote con el "médico", alguien que posee la doctrina de los preceptos necesarios para la salud del cuerpo, pero sin ninguna potestad coactiva para obligar a nadie a cumplirlos ${ }^{14}$. La función del sacerdote es, por tanto, la de un "médico" de la salud de las almas: la enseñanza y exhortación de lo que hay que creer y practicar con necesidad para el logro de la salud eterna. Con verdadera maestría -no exenta, quizá, de cierta ironía- Marsilio invierte los términos de la tradicional interpretación del papado para reconocer que Pedro efectivamente tiene "las llaves" del Reino de los Cielos: pero el que lleva las llaves sólo es el "portero" (claviger) y no por ello juez con potestad coactiva. Tal como el carcelero terrenal se limita a guardar las llaves de la cárcel en la que se encierra a los condenados por la sentencia coactiva del juez, Pedro representa el "portero" de la "cárcel de las almas" ${ }^{15}$. 
9 Además de esta autoridad, que es constitutiva y propia del sacerdocio, Marsilio reconoce otra especie de autoridad que puede corresponderle y que significativamente califica como "accidental" o "separable": es aquella por la cual un sacerdote entre otros tiene cierto poder para dirigir y mandar sobre el resto en lo relativo a la administración del templo y de todo lo relativo al culto, así como la distribución de los bienes temporales en favor de los pobres que quedan al cuidado de la Iglesia, etc.. Bajo esta forma entiende Marsilio aquel tipo de autoridad de la que está investido el obispo. Si en cuanto a la autoridad esencial -la potestas ordinis que Marsilio identifica con la potestas clavium - el sacerdote no tiene ninguna autoridad coactiva, tampoco le corresponderá según este tipo peculiar de autoridad. La estrategia de Marsilio consistirá en asimilar esta jurisdicción a una cierta autoridad tal que pueda implicar alguna especie de subordinación, pero totalmente desprovista de un contenido político. Traducido a los términos de la Política aristotélica, esto se encuadra bajo la esfera de la economía, la administración de la casa, la cual implica ciertamente alguna clase de gobierno, pero que es específicamente diferente respecto del gobierno de la pólis. Así es como Marsilio se apoya en la tradición del Imperio bizantino para decir que los obispos son "yconomi reverendi", administradores de una casa, ni más ni menos que la casa de Dios, es decir, del templo ${ }^{16}$. Este peculiar sentido del gobierno de la "Iglesia" que Marsilio concede a la jerarquía eclesiástica se ajusta perfectamente al momento histórico que Iogna-Prat ha caracterizado como aquel en que la Iglesia ha pasado a asentarse o constituirse en torno de un lugar central: el edificio o templo ${ }^{17}$. Los sacerdotes son no son más que "custodios" o administradores del Templo. Sin embargo, ese ámbito de la Iglesia-templo ha quedado reducido, literalmente vaciado de significación "política", e integrado en el ámbito mayor de la Iglesia-comunidad, la communitas fidelium, que será gobernada por el príncipe cristiano.

\section{La indistinción entre sacerdote y obispo en la Iglesia primitiva}

Para demostrar la igualdad de los sacerdotes en cuanto a la autoridad esencial o potestad de las llaves, Marsilio no tiene más que remitirse nuevamente a las fuentes evangélicas sobre el status de la Iglesia primitiva. Si el célebre pasaje de Mateo relativo a la "concesión Petrina" podría indicar un primado de Pedro, Marsilio le contrapone una cantidad de pasajes en que las expresiones de Cristo respecto de la institución de la eucaristía, de la confesión y de la misión evangélica se hacen significativamente en plural ${ }^{18}$, lo que demuestra claramente que no hubo preferencia por un apóstol en particular. Del mismo modo se apoya Marsilio en las referencias del Nuevo Testamento para dar a entender que Pedro no tuvo una autoridad mayor que Pablo ni ningún "primado" especial sobre el resto de los apóstoles ${ }^{19}$. Más aún, a partir del Nuevo Testamento, según Marsilio, no hay mayor fundamento para establecer que Pedro haya sido obispo en Roma o, en todo caso, que haya tenido autoridad mayor que Pablo ${ }^{20}$.

11 Si esto es así respecto de la autoridad carismática y las funciones estrictamente espirituales de los apóstoles, con mayor razón atribuye Marsilio una igualdad jurisdiccional entre ellos en los primeros tiempos de la Iglesia. En pocas palabras, Marsilio sostiene que en la Iglesia primitiva no había distinción entre obispo y sacerdote. Según las fuentes de Marsilio, "présbyter" y "epíscopos" eran términos intercambiables en la Iglesia primitiva: uno hacía alusión a la edad (¡lat.=senior!) y otro a la dignidad por la supervisión sobre otros (¿lat.=superintendens?) ${ }^{21}$. Para Marsilio esta otra especial autoridad jurisdiccional -de índole "económica", en su interpretación- tuvo un origen 
histórico. Surgió tiempo después, con el acrecentamiento de la Iglesia, su expansión geográfica y la consecuente complejización de las tareas:

“... para evitar el escándalo y el cisma, eligieron los sacerdotes uno de entre ellos que dirigiera a los otros y ordenara cuanto concierne a ejercer el oficio y el servicio eclesiástico [...] a fin de que no se obstaculizara la administración y el servicio en los templos, si cada uno obrara a su voluntad o a veces en forma indebida ..." ${ }^{22}$

De hecho, la mayoría de los testimonios del Nuevo Testamento y, en especial, de los Hechos, muestran cómo los Apóstoles tomaban en común las decisiones más importantes, disponían en común de los bienes de la comunidad primitiva y elegían en común a los discípulos y encargados de tareas específicas ${ }^{23}$. Con posterioridad al tiempo de los apóstoles y al crecimiento de esta Iglesia, la institución de esta autoridad jurisdiccional quedó en manos de la propia totalidad de fieles cristianos en aquella comunidad sobre la cual debía designarse el obispo. En suma, esta autoridad jurisdiccional es, para Marsilio, de institución humana ${ }^{24}$.

\section{La autoridad de excomunión, de castigar las herejías y la institución de los oficios eclesiásticos}

13 Tras haber despojado al sacerdocio de todo contenido político, tanto en su aspecto sacramental como en el jurisdiccional, remitido incluso éste a la institución por parte de la comunidad de los fieles, Marsilio reasigna la fuente última del gobierno de la Iglesia en todas aquellas instancias que reclamaba para sí la autoridad papal. Las principales acciones y determinaciones sobre las que se constituía la figura de la "monarquía papal" son ahora depositadas en la instancia fundante de la autoridad política temporal. En la primera dictio, ésta era la corporación de la totalidad de los ciudadanos o su parte preponderante (universitas civium aut eius valentior pars); en la segunda dictio, el respectivo papel tutelar lo tendrá ahora la análoga figura del "legislador humano fiel" o la "totalidad de los fieles" (universitas fidelium), cuya autoridad -tal como sucede en la primera dictio- puede ser eventualmente representada o delegada en "aquel que gobierna en virtud de su autoridad" (ipsius auctoritate principans). Marsilio transpone así al plano eclesiológico la misma configuración teórica de la soberanía popular que había sustentado en su filosofía política natural, con el consecuente traslado de todas las ambigüedades y aspectos controvertidos que ésta contiene.

14 En rigor, el interés de Marsilio en estos diversos tópicos del plano eclesiológico se explica por la eventual repercusión que tienen en la estabilidad del régimen político. La preocupación de Marsilio sigue siendo aquí, por tanto, sustraer a la jerarquía eclesiástica toda posibilidad de ingerencia en el ámbito político y asegurar, a su vez, su subordinación en todos sus niveles a la autoridad del legítimo gobernante de la comunidad civil. El caso del poder de excomunión confirma esto claramente. La excomunión es una pena que excede el ámbito de la ley divina, puesto que acarrea consecuencias también para el estado en este mundo: mediante la excomunión, al reo no sólo se le aplica una pena para el mundo futuro, sino que es difamado públicamente y privado de la convivencia con los demás integrantes de la comunidad civil. Un juicio incierto o incorrecto por parte de un sacerdote o de un "colegio particular" podría acarrear graves consecuencias para la vida política. De allí que la institución del juez que ha de examinar, juzgar o absolver al acusado de la difamación pública y la separación de la comunidad de los fieles (fidelium consortio) le corresponde a la totalidad de los fieles en 
aquella comunidad en la que haya de desarrollarse tal juicio, o a su superior, o al concilio general, aunque para tal juicio se requiera la voz y acción del sacerdote. Una vez más, el sacerdote actúa como "juez" en el sentido de perito y experto; su función es asesorar acerca de los crímenes por los cuales alguien debería ser apartado de la comunidad de los fieles para que no corrompa a otros. Pero el juicio acerca de si el reo efectivamente ha cometido o no tal crimen no corresponde al sacerdote o al colegio sacerdotal, sino a la totalidad de los fieles de aquella comunidad, o a su superior ${ }^{25}$. La "demostración" o confirmación por la razón de esto devela el interés dominante de Marsilio: el caso peculiar de la excomunión del príncipe. Si cualquier obispo o presbítero pudiera excomulgar sin el consenso de la totalidad de los fieles se seguiría que los sacerdotes podrían privar de sus gobiernos a todos los reyes y príncipes, pues la excomunión de éstos implica la de toda la multitud que quiera obedecerle ${ }^{26}$.

Finalmente, la designación de los obispos es también remitida a la autoridad suprema del legislator humanus fidelis. Al testimonio acerca de la institución de los primeros discípulos y la imposición de las manos por parte de los apóstoles en conjunto ${ }^{27}$ y a ciertos testimonios históricos acerca de la "elección de los obispos" ${ }^{28}$ Marsilio acompaña una serie de "pruebas racionales" que no son sino la extensión al plano eclesiológico de los mismos argumentos principales con los que se demostró en la primera dictio que pertenecía a la universitas civium o su valentior pars la institución de las leyes y de la parte gobernante ${ }^{29}$. Por su autoridad jurisdiccional el obispo no tiene un poder sacramental especial mayor que el de otro sacerdote, sino que sólo está como "destinado" o designado a un lugar o provincia específica. Por ello es razonable pensar que, durante el tiempo en que los cristianos vivían en comunidades gobernadas por un príncipe infiel, la institución de los obispos se hizo por la elección conjunta de los apóstoles o de la asamblea de los fieles que vivieran en la región; con posterioridad, en las "comunidades fieles ya acabadas", esto es, en los estados totalmente cristianizados, la designación se realizó por la totalidad de los fieles en aquel lugar o provincia sobre el cual debía instituirse el ministro y, eventualmente, por aquel o aquellos a quienes hubiere concedido tal autoridad ${ }^{30}$.

\section{Las definiciones en materia doctrinaria y la autoridad del concilio}

16 Como se ha dicho, Marsilio no intenta quebrar la unidad de la Iglesia. La fe es una y universal; hay un conjunto de verdades reveladas y preceptos impartidos por Dios que todos los cristianos deben conocer y cumplir necesariamente con el fin de obtener la salvación ${ }^{31}$. La fuente primaria en la que se hallan estas verdades es la sagrada escritura, a la cual sólo hay que atenerse estrictamente y en primer término respecto de las consideradas escrituras canónicas. Pero como la escritura puede contener "pasajes dudosos", de la correcta o incorrecta interpretación de los mismos no sólo se seguiría la eventual separación o cisma de la Iglesia, sino el peligro de perder la vida eterna. En vano habría establecido Cristo la ley de salvación eterna si no hubiera abierto el sentido de su comprensión. Por consiguiente, es posible y necesario "determinar" o "fijar" el sentido correcto de los pasajes dudosos de la escritura. Y aquí Marsilio nuevamente desplaza lo que constituía uno de los ejes de la función directriz del papado hacia una nueva instancia última de autoridad dentro de la Iglesia: la regulación y supervisión del cuerpo doctrinario fundamental de la fe, anteriormente sustentada en el dogma de la infalibilidad papal, pasa ahora a manos del inspirado concilio general de los cristianos. 
17 En su particular visión conciliarista ${ }^{32}$ Marsilio interpreta al concilio como la continuidad histórica natural de los apóstoles y lo considera igualmente inspirado por el espíritu santo ${ }^{33}$. Marsilio traslada al concilio un similar perfil soberano y las mismas relaciones de representación que había establecido para la universitas civium: la autoridad de determinar el sentido de los pasajes dudosos de la escritura corresponde a

"La autoridad principal de esta determinación, mediata o inmediata, es del solo concilio general de los cristianos o de su parte preponderante o de aquellos a quienes la totalidad de los fieles cristianos haya concedido esta autoridad, de suerte que todas las provincias y comunidades notables del mundo, según sus legisladores, sean uno o varios, y según la proporción en cantidad y calidad de las personas, elijan hombres fieles ..." 34

18 El concilio marsiliano está compuesto no sólo por sacerdotes, sino también por laicos, se entiende, por hombres de virtud aprobada que sean peritos o expertos en la ley divina ${ }^{35}$. Su competencia abarca también la determinación del ritual litúrgico y demás prescripciones relativas al culto. La autoridad coactiva que dispone su convocatoria no podrá ser otra que el "legislador humano fiel carente de superior", puesto que ya se ha demostrado que ningún obispo o colegio de sacerdotes tiene ninguna autoridad coactiva ni ninguna otra autoridad especial sobre el resto de los sacerdotes que no esté concedida por el legislador fiel.

19 En apoyo de su tesis, Marsilio nuevamente trae a colación las correspondientes pruebas escriturarias, históricas y racionales. Los Hechos constituyen, una vez más, una de las fuentes privilegiadas para demostrar cómo no fue Pedro solo o un "colegio particular" quien decidió, por ejemplo, acerca de la cuestión de los incircuncisos, sino todos los apóstoles junto con los "expertos" de la comunidad cristiana ${ }^{36}$. Los testimonios históricos dan cuenta de cómo efectivamente los primeros concilios fueron siempre convocados por los emperadores cristianos, a los cuales asistían acompañados por su consejo de oficiales. Finalmente, Marsilio vuelve a insistir en las mismas pruebas racionales de la primera dictio ya extendidas a la demostración de la causa de la institución de los oficios eclesiásticos. Pero Marsilio se explaya, además, en una prueba racional por la negativa: la autoridad en cuestión no pertenece ni puede pertenecerle al solo obispo romano y a su colegio de cardenales. El caso planteado por Marsilio es el de la eventualidad de que un papa caiga en herejía, una referencia directa a la reciente experiencia histórica de Juan XXII y su condena de la tesis de la pobreza evangélica en la bula Cum inter nonnullos. Esta peculiar situación - que habla a las claras de la crisis por la que atraviesa la institución papal en la baja Edad Media- constituye el mejor ejemplo para corroborar la tesis marsiliana: mientras que una persona singular o un colegio privado, es decir, minoritario, puede estar expuesto al error por "ignorancia o malicia", tal imputación no puede caberle al concilio en el que están representada la totalidad o la mayor parte de los fieles ${ }^{37}$.

Aunque la determinación de cuál sea la autoridad que fije el sentido de los pasajes dudosos de la escritura tiene que ver con la conservación del cuerpo dogmático de la Iglesia $y$, por ende, se trata de una autoridad en materia doctrinal estrictamente religiosa, la cuestión tampoco carece de implicancias políticas. De lo que se trata es de establecer, respecto de lo que ha de creerse, qué es lo necesario para obtener la salvación. Y precisamente éste fue otro de los elementos que utilizó el papado para expresar su intención de someter a su esfera la conducta del poder temporal. La Unam Sanctam de Bonifacio VIII reclamaba justamente como "necesario para la salvación" el que "toda criatura humana esté sujeta al romano pontífice. Este tipo de abuso es denunciado 
manifiestamente por Marsilio: las "decretales" mediante las cuales los papas pretendían imponer una jurisprudencia a su favor, no sólo no son auténticas leyes puesto que carecen de su esencial carácter coactivo en cuanto no han sido promulgadas en la forma y por la instancia debida-, sino que tampoco tienen validez dentro del gobierno de la Iglesia: los decretos superiores que la rigen pertenecen únicamente al concilio ${ }^{38}$.

\section{La resignificación del primado de la iglesia romana}

Después de haber montado la nueva sede de la autoridad de gobierno de la Iglesia, el concilio, queda por ver cómo se resignifica el papel del obispo romano. Curiosamente no hay por parte de Marsilio una impugnación total de la figura del primado de roma, o de la "cabeza" de la Iglesia: la necesidad y la tradición han conquistado para la Iglesia romana un lugar especial, pero que de ningún modo puede compararse a la desproporcionada ambición del papado. De todo lo dicho queda perfectamente claro cuáles son los sentidos en que no puede ni debe entenderse el que un obispo o Iglesia particular se constituya en "cabeza" de la Iglesia: (a) no en cuanto que ella defina y determine la interpretación de los sentidos dudosos de la Escritura, lo dogmas fundamentales y los rituales del culto, puesto que se ha demostrado que ello corresponde al legislador fiel o al concilio; (b) mucho menos en el sentido de que a ella le estén sometidos los clérigos y sacerdotes de todo el mundo con jurisdicción coactiva, puesto que se ha demostrado que tal jurisdicción no pertenece a ningún sacerdocio; (c) tampoco en el sentido de que a ella le corresponda la institución de los oficios secundarios eclesiásticos y la distribución de los beneficios eclesiásticos, pues se ha demostrado que tal institución no le pertenece a ningún obispo o colegio particular, sino al legislador humano fiel ${ }^{39}$. No resta sino concluir que, si ha de haber alguna "cabeza" de la Iglesia, lo será en cuanto a ella le corresponda -en compañía del colegio sacerdotal que el concilio o el legislador fiel le hubiera asignado- comunicar y sugerir al legislador humano fiel carente de superior la necesidad de convocar al concilio general, si surgiera un caso para la fe o necesidad evidente de los fieles denunciado ante él. Además, le correspondería el papel de presidir el concilio, dirigir el debate y llevar su registro público, comunicar sus decisiones a las otras Iglesias y velar por su cumplimiento con penas eclesiásticas, siempre conforme a la autoridad del concilio o el legislador ${ }^{40}$.

Sólo en este único y último sentido puede una Iglesia y obispo ser la principal y cabeza entre las restantes, sin jurisdicción coactiva alguna; más aún, Marsilio llega a sugerir que, en rigor, el que haya tal cabeza no constituye un precepto de la ley divina, "pues aún sin esto puede salvarse la unidad de la fe, aunque no tan fácilmente." ${ }^{41}$ En última instancia, el primado de Roma que extrañamente retiene Marsilio tiene un sentido mera y exclusivamente tradicional: el puesto destacado de Roma dentro de las otras Iglesias, por la eminencia de algunos de sus primeros obispos o por la sabiduría de su colegio sacerdotal, le han valido -se sobrentiende, en los primeros tiempos de la Iglesia y no en el actual momento de corrupción y decadencia de la Iglesia romana que acusa Marsilio- una especial reverencia y respeto que le ofrecieron las otras Iglesias en forma espontánea y bajo ninguna coacción ${ }^{42}$.

Con este último punto se confirma que el paduano no tiene ningún interés en destruir el aparato de la jerarquía eclesiástica en sí misma, ni de cancelar el aspecto público y 
oficial de la Iglesia: las verdades fundamentales de la fe que se hallan expresadas en la Revelación constituyen un cuerpo doctrinario universal y único, firmemente custodiado por la instancia superior a cargo de la preservación de su integridad, el concilio. De allí en más se mantiene el aparato del magisterio de la Iglesia que incluye las interpretaciones "aprobadas" de los doctores y santos intérpretes de la Iglesia; lo que se aparte decisivamente de esta ruta ha de ser calificado como herejía. La Iglesia no ha perdido finalmente ninguno de los aspectos de su autocomprensión en términos jurídicos: la ley divina es un precepto coactivo que impone una pena a sus transgresores en el otro mundo -y no en éste-, por más que el juez competente es sólo Cristo y no sus sacerdotes. El "romanismo" que Marsilio proyecta sobre su teoría política natural, se extiende también a su eclesiología en forma tal que termina conservando el papel tradicional del primado de Roma sobre las restantes Iglesias de la cristiandad, aunque ese primado sea ampliamente revisado y resignificado.

\section{Los períodos de la historia marsiliana de la Iglesia} reforma. En casi todos ellos se verifica, de algún modo, la proyección Desde las primeras reorganizaciones de las órdenes monásticas y las fundaciones de las órdenes mendicantes hasta los diversos movimientos de la Reforma, el esfuerzo de quienes se sintieron movidos a renovar el vigor de la fe, a reafirmar las reglas de conducta debilitadas o a superar la crisis moral de la Iglesia, siempre tuvo un estandarte preferido en el locus del retorno al ideal de la Iglesia primitiva. En cada caso, se trataba de resignificar el valor de aquella primera comunidad de los discípulos de Jesús, tal como está relatada en los Hechos de los Apóstoles, proyectando en ella la realización de las nuevas exigencias que la historia planteaba. Marsilio no hace un aporte original por el sólo hecho de volver sobre este tópico, sino, en todo caso, por la forma en la que lo introduce y los objetivos que lo orientan. El "retorno a los orígenes" tendrá para Marsilio el sentido de aproximarse al estadio originario en el que puede apreciarse fielmente el modelo debido de las relaciones entre la Iglesia y el poder político en su estado "puro", desprovisto de sus posteriores tergiversaciones y corrupciones.

A lo largo de toda su argumentación eclesiológica, Marsilio va aportando una serie de "pruebas históricas" basadas en el Nuevo Testamento, en las fuentes tradicionales de la historia de la Iglesia y también en testimonios históricos de origen secular. Si seguimos la reconstrucción marsiliana de la historia de la Iglesia, es posible advertir una división en cuatro grandes períodos: (i) el momento fundante y originario durante la vida de Cristo; (ii) el período inmediatamente posterior, el de las primeras comunidades cristianas que se desarrollaron en el ámbito de comunidades políticas infieles, hasta los tiempos de Constantino; (iii) el período que va desde los tiempos de Constantino hasta los acontecimientos más recientes; (iv) el momento contemporáneo, caracterizado por la crisis moral y la corrupción de la Iglesia a causa de las ambiciones políticas del papado.

La primera de estas cuatro fases o períodos en la historia marsiliana de la Iglesia representa el momento fundacional por el cual se toma conocimiento de los mandatos expresos e inmediatos de Cristo. Allí se confirma que la pretensión de Cristo al fundar la Iglesia no fue la de establecer un dominio temporal, y que, en todo caso, del especial "Reino" que Cristo proclamó no puede seguirse ninguna jurisdicción de la Iglesia sobre

Bulletin du centre d'études médiévales d'Auxerre | BUCEMA, Hors-série nº 7| 2013 
los dominios temporales, sino por el contrario: el reconocimiento de y la subordinación a las autoridades constituidas.

El segundo período considerado por Marsilio, el de la Iglesia primitiva o las primeras comunidades de los cristianos hasta los tiempos de Constantino, da cuenta del período de desarrollo y expansión del cristianismo en un ámbito político pagano hasta el momento de su definitiva integración a éste, vale decir, hasta la definitiva cristianización del Estado. Este singular período representa el punto crucial de toda la argumentación histórica de Marsilio. De hecho, constituye el momento más cercano al momento fundacional y, por tanto, el más próximo al sentido originario. Se trata de un momento de transición, en el que todavía se percibe claramente el sentido místico y la acción puramente sobrenatural del sacerdocio - tal como fue fundado por Cristo-, pero en el que la Iglesia no había llegado a crecer en extensión y complejidad para dar lugar a las instituciones eclesiástias de origen humano, o apenas comenzaba a hacerlo. obviamente se trata del período en que el proceso de "romanización" de la Iglesia aún se está llevando a cabo y, por tanto, es el momento en que abundan las mayores fuentes para impugnar el primado de la Iglesia de Roma o, en todo caso, para probar su origen histórico y sus fundamentos meramente tradicionales.

En los testimonios correspondientes a este período basa Marsilio sus conclusiones sobre la igualdad carismática y jurisdiccional de los apóstoles, los procedimientos electivos acompañados por la multitud de los fieles y las decisiones comunes en materia doctrinal. Es decir que este período es la prueba histórica principal de tres de los más importantes puntos de la eclesiología marsiliana: el origen histórico de la autoridad jurisdiccional del sacerdocio, la institución de los obispos por parte del legislador humano fiel y la teoría de la infalibilidad conciliar. Pero este período es también el de las "comunidades fieles no acabadas". Por tales entiende Marsilio aquellos estados políticos infieles en los cuales la universitas fidelium aún no coincide de hecho con la universitas civium: la comunidad cristiana representa una minoría que todavía se desenvuelve en un ámbito secular pagano. Pero tampoco esta Iglesia primitiva e insuficientemente jerarquizada se ajusta al perfil propio de la Iglesia de Marsilio: la Iglesia que Marsilio conoce es una Iglesia pública e institucionalizada, plenamente identificada con la comunidad política a la cual pertenece; una civitas que reconoce como una de sus "partes" u oficios a un único sacerdocio verdadero ${ }^{43}$ y que es gobernada por un príncipe fiel ${ }^{44}$. Marsilio no pretende, por tanto, retroceder a los tiempos de la deficiente institucionalidad de la Iglesia, sino rescatar en sus orígenes las bases de una institucionalización correcta y congruente tanto con la verdad revelada como con la suficiencia de la vida política secular.

El período que sigue al de la Iglesia primitiva está marcado por un hito que, a juicio de Marsilio y de otros intérpretes, delimita todo un "antes y después" en la historia de la Iglesia: la denominada "donación de Constantino". El célebre documento apócrifo, cuya autenticidad no fue cuestionada sino hasta la aparición de la crítica filológica renacentista, fue un singular eje de la polémica entre los partidarios del papado y del poder secular. Como todos los autores medievales, Marsilio no intenta poner en duda la veracidad de este supuesto testimonio histórico, sino reinterpretarlo ajustándolo a los términos de su propia teoría ${ }^{45}$. Es cierto que la donatio aparece como uno de los argumentos recurrentes del papado para fundamentar su pretensión de una jurisdicción coactiva universal. En todo caso, lo manifiesto es la concesión del primado de la Iglesia romana sobre las otras sedes: Antioquía, Constantinopla y Jerusalén. Pero 
el hecho de que los papas hayan invocado con posterioridad el pretendido título de la plenitudo potestatis devela, en la opinión de Marsilio, la debilidad de este argumento histórico: sea porque el alcance del mentado don o privilegio no está en claro, o porque acaso posteriormente expiró, o porque, aún siendo válido, la pretendida jurisdicción no se extiende a los restantes principados del mundo, ni al del Emperador de los romanos ${ }^{46}$. Si los papas se atribuyen la jurisdicción coactiva sobre todos los obispos y presbíteros de este mundo por la cesión de Constantino, en todo caso, esto es la mejor prueba de que éste tuvo una jurisdicción de tal tipo sobre ellos con anterioridad a la cesión ${ }^{47}$.

El último momento de esta revisión marsiliana de la historia de la Iglesia está dado por la época contemporánea, que para Marsilio representa el momento culminante de la corrupción moral e institucional de la Iglesia. El nuevo escenario histórico que refleja este momento es el del conflicto entre los papas modernos y los príncipes seculares. Si los fundamentos históricos anteriores se remitían a la historia relatada en el Nuevo Testamento o a los testimonios históricos seculares del Imperio, ahora se trata, lisa y llanamente, de una referencia directa a los acontecimientos políticos más recientes, en particular, la lucha entre Bonifacio VIII y Felipe el hermoso y, desde ya, la polémica entre Juan XXII y Luis de Baviera, que da origen al tratado. Según Marsilio, después de los tiempos de la donación de Constantino, fue costumbre que los emperadores debidamente elegidos e instituidos fueran bendecidos o coronados por los pontífices romanos, en una actitud que mostraba la debida reverencia de un príncipe fiel a la figura de Cristo, simbolizada en el preclaro obispo de Roma; tratábase de una ceremonia o de una solemnidad que en nada añadía o modificaba el status del poder político que ya habían adquirido ${ }^{48}$. Con posterioridad, los obispos romanos, por las ambiciones políticas y materiales que actualmente se les conoce, tergiversaron el sentido de esta ceremonia y se arrogaron injustificadamente la potestad de conferir el principado o la jurisdicción coactiva, desconociendo la naturaleza y la fuente de la autoridad de los electores.

31 En este momento de la argumentación se advierte cómo Marsilio se apoya claramente en las estructuras y prácticas tradicionales del Sacro Imperio. Según Marsilio, el obispo romano

“... ignora, en efecto, cuál es la virtud y la razón de la elección, y a causa de qué esa potestad recae sobre la parte preponderante de quienes deben elegir; [e ignora] por qué su efecto no debe ni puede depender de la voluntad de un sólo y único individuo [...], sino sólo del legislador sobre el cual el príncipe debe ser instituido, o bien sólo de aquellos a los cuales el mismo legislador hubiera concedido tal autoridad ..." ${ }^{49}$.

32 Ni siquiera puede argumentarse que al obispo romano le corresponda confirmar la elección, por la precaución o la sospecha de que se elija a un príncipe hereje o que pueda caer en herejía: Marsilio reivindica el carácter cristiano de esta cúpula electiva. La elección no necesita de la aprobación del pontífice romano: "pues se celebra y lleva a cabo por tres solemnes arzobispos cristianos, y conjuntamente a su vez por cuatro príncipes seculares fieles, con los cuales, y en acuerdo con los mencionados prelados, se consuma la elección." 50

Como hemos visto, el problema peculiar que presenta la causa de discordia que Marsilio aspira a extirpar de raíz es el hecho de que representa un cruce entre el plano natural y el sobrenatural: supone una intromisión del plano sobrenatural en la fundamentación de la existencia y los fines de la comunidad política natural y, paralelamente, una perversa extensión al plano sobrenatural -al que pertenece la Iglesia en su aspecto 
místico y carismático-, de las estructuras de poder exclusivas de la comunidad política natural. Frente a esta concepción el Defensor pacis efectúa una disolución de esta unidad mediante dos operaciones fundamentales: una naturalización de la política y una despolitización de la Iglesia, esto es, una reconstitución de los fundamentos explicativos, históricos y normativos de la comunidad política sobre una base natural, y una reconstrucción de la explicación, la historia y la normatividad de la Iglesia que la retrotraiga a sus orígenes y a su esencia extra-política. Tanto en uno como en otro camino, Marsilio está lejos de ser un pensador laico o un promotor de la "separación entre Iglesia y Estado". Tampoco le hace suficiente justicia el reconocimiento bajo la dudosa categoría de "precedente", en este caso, de alguno de los aspectos del ideario de la filosofía política moderna. En definitiva, Marsilio de Padua no constituye una "excepción" al horizonte histórico de su época, en el cual queda claramente inscripto. En todo caso, su excepcionalidad se halla en la radicalidad de la respuesta que ha ofrecido para el problema político de su tiempo, una radicalidad que todavía sigue sorprendiendo para los que se sitúan más allá de ese horizonte histórico.

\section{NOTAS}

1. Cf. G. GARNETT, Marsilius of Padua and the Truth of History, Oxford, 2006, p. 14-45.

2. Cf. MARSILIUS vON PADUA, Defensor pacis. Herausgegeben von R. Scholz. Hanovre, 1932-1933 [=DP], I i, 3, p. 5.

3. Cf. DP I xix, 3-4, p. 126-7 ; I xix, 8-9, p. 131-132.

4. Cf. J. QUILLET, La philosophie politique de Marsile de Padoue, Paris, 1970, p. 168.

5. Cf. Juan xviii, 36.

6. Cf. Juan xix, 11.

7. Cf. Mateo xxii, 21.

8. Cf. Rom. xiii, 1-5.

9. Cf. DP I x, 4, p. 49-50 ; II viii, 5, p. 224.

10. Cf. DP II iv, 6, p. 190-191; II ix, 2, p. 232.

11. Cf. W. UllmanN, , Principios de gobierno y política en la Edad Media. Trad. cast. Madrid, 1985, p. 44-45.

12. Cf. DP I xix, 5, p. 129 ; II xv, 10, p. 336.

13. Cf. DP II ii, 8, p. 150-1.

14. Cf. DP II vi, 12 ; vii, 4 ; ix, 2,3 ; $x, 9$.

15. Cf. DP II vii, 3, p. 217-218.

16. Cf. DP II xv, 8, p. 334.

17. Cf. D. IOGNA-PRAT, La Maison Dieu. Une histoire monumentale de l'Église au Moyen Âge, v. 800-v. 1200, Paris, 2006.

18. Cf. Lucas xii, 19 ; Juan $\mathrm{xx}, 21-23$; Mateo xxviii, 19.

19. Gál. ii, 6-11.

20. Cf. DP II xvi, 16-18, p. 352-55.

21. Cf. DP II xv, 5, p. 329.

22. Cf. DP II xv, 6, p. 331.

23. Cf. Hechos iv, 34-5; vi, $2-6$; xv, 22. 
24. «Apparet eciam ex iam dictis quod alia est quedam humana institucio, qua sacerdotum unus aliis prefertur, que eciam sacerdotes ad certas provincias et populos erudiendos et instruendos in lege divina, et ministrandis sacramentis ad dispensandis temporalibus, que beneficia ecclesiastica diximus, statuuntur. » DP II xvi, 10, p. 336.

25. Cf. DP II vi, 12, p. 209-211.

26. Cf. DP II vi, 13, p. 214-215.

27. Hechos vi, 2-6.

28. Cf. DP II xv, 8, p. 333.

29. Cf. DP II Xvii, 11, p. 265 ; I xii, 5-7, p. 65-68; I Xv, 2, p. 85.

30. Cf. DP II xvii, 8, p. 362.

31. Cf. DP II xviii, 8, p. 380.

32. En general, más allá de alguna mención o relativa influencia en autores posteriores, suele entenderse que la visión radicalizada de Marsilio no fue recogida por el conciliarismo del S. XV : cf. F. OAKLEY, The Conciliarist Tradition. Constitutionalism in the Catholic Church 1300-1870, Oxford, p. 102-105.

33. Cf. DP II xix, 3, p. 386.

34. Cf. DP II xx, 2, p. 393.

35. Cf. ibid..

36. Cf. Hechos Xv, 6-22 ; 25-28.

37. Cf. DP I xx, 6-7, p. 396-397.

38. Cf. DP II xx, 8, p. 397-398.

39. Cf. DP II xxii, 1-3, p. 420-422.

40. Cf. DP II xxii, 6, p. 424-425.

41. « ... quamvis non sit lege divina preceptum, quoniam et sine hoc fidei unitas, licet non sic faciliter, salvaretur ... : cf. DP II xxii, 6, p. 426 $6^{3-5}$.

42. Cf. DP II Xxii, 8, p. 427-8; 16, p. 435-436.

43. Cf. DP I v, 14, p. 28.

44. Cf. DP II v, 5, p. 188-189; II v, 7, p. 193.

45. C. F. BERTELlONI, "'Constitutum Constantini' y 'Romgedanke' : la donación constantiniana en el pensamiento de tres defensores del derecho imperial de Roma: Dante, Marsilio de Padua y Guillermo de Ockham » en Patristica et mediaevalia, vol. 3 (1982) p. 21-46.

46. Cf. DP I xix, 8, p. 131.

47. Cf. DP II xi, 8, p. 262.

48. Cf. DP II xvi, 4, p. 489-490.

49. Cf. DP II xxvi, 5, p. 491-492 (subr. nuestro).

50. Cf. DP II xxvi, 9, p. 496.

ÍNDICE

Mots-clés: eclesiología, filosofía política medieval 


\section{AUTOR}

JULIO A. CASTELLO DUBRA

Université de Buenos-Aires, CONICET 